\title{
CONDIÇÕES AMBIENTAIS DE PROPRIEDADES AGRÍCOLAS E PERCEPÇÃO AMBIENTAL DE PRODUTORES RURAIS DO MUNICÍPIO DE DOBRADA - SÃO PAULO, BRASIL
}

\author{
ENVIRONMENTAL CONDITIONS OF THE \\ AGRICULTURAL PROPERTIES AND ENVIRONMENTAL \\ PERCEPTION OF RURAL PRODUCERS IN THE \\ DOBRADA' CITY - SÃO PAULO' STATE
}

\author{
Juliana Heloisa Pinê Américo ${ }^{1}$, Sérgio Luís de Carvalho², \\ Mônica de Lima Gonzaga ${ }^{3}$, Elizete Aparecida Checon Freitas \\ Lima $^{2}$, Carlos Augusto Morais e Araújo ${ }^{4}$ \\ ${ }^{\mathbf{1}}$ Departamento de Biologia e Zootecnia da Faculdade de Engenharia de Ilha Solteira \\ (FEIS/UNESP). E-mail: americo.ju@gmail.com \\ ${ }^{2}$ Departamento de Biologia e Zootecnia da Faculdade de Engenharia de Ilha Solteira \\ (FEIS/UNESP). E-mail: sergicar@bio.feis.unesp.br e eacflima@bio.feis.unesp.br \\ ${ }^{3}$ Departamento de Engenharia Civil da Faculdade de Engenharia de Ilha Solteira \\ (FEIS/UNESP). E-mail: monicagonzaga@gmail.com \\ ${ }^{4}$ Departamento de Fitotecnia, Tecnologia de Alimentos e Sócio-Economia da Faculdade \\ de Engenharia de Ilha Solteira (FEIS/UNESP). E-mail: coryong@agr.feis.unesp.br
}

\begin{abstract}
RESUMO
O objetivo do presente trabalho foi realizar investigações junto a diversos produtores rurais no município de Dobrada - SP, procurando avaliar os principais problemas ambientais em suas propriedades agrícolas, e como estes são tratados de acordo com o grau de conscientização dos agricultores e pecuaristas. A pesquisa procurou identificar algumas ações no meio rural que contribuem de forma negativa para os processos de degradação ambiental. Por meio das informações obtidas foi possível determinar a estrutura e a caracterização socioeconômica dessas propriedades, bem como avaliar a percepção dos proprietários quanto à necessidade da preservação ambiental associada às práticas agrícolas. Para tanto, houve visitas a 30 propriedades rurais de diferentes tamanhos e aplicação de um questionário com questões abertas e de múltipla escolha, enfocando os principais problemas relacionados à degradação ambiental. As questões abordaram diferentes aspectos relacionados à contaminação dos recursos hídricos, uso e conservação do solo, proteção de matas nativas e ciliares, disposição de resíduos sólidos e líquidos, utilização de agrotóxicos e possíveis casos de contaminação, caça e pesca predatórias, entre outras ocorrências, procurando-se, também, avaliar a importância que o produtor rural e agregados atribuem aos recursos naturais e ao meio ambiente.
\end{abstract}

Palavras-chave: Conservação ambiental. Recursos naturais. Degradação ambiental. Educação ambiental. 


\begin{abstract}
The aim of this study was to research with several farmers in the Dobrada' City, attempting to assess the main environmental problems in their farms, and how they are treated according to the degree of awareness of farmers and ranchers. The survey sought to identify some actions in rural areas that contribute negatively to the processes of environmental degradation. Through the information obtained it was possible to determine the structure and socio-economic status of these properties, and evaluate the perception of the owners as the need for environmental conservation associated with agricultural practices. To this end, there was 30 visits to farms of different sizes and application of a questionnaire with open questions and multiple choice, focusing on the key issues related to environmental degradation. The questions deal with different aspects related to contamination of water resources use and soil conservation, protection of native forests and vegetation, disposal of solid and liquid waste, use of pesticides and possible cases of pollution, hunting and fishing, among other events, looking also evaluate the importance that the farmer and his household attributed to natural resources and the environment.
\end{abstract}

Keywords: Environmental conservation. Natural resources. Environmental degradation. Environmental education.

\title{
1. INTRODUÇÃO
}

As ações antrópicas sobre ambientes naturais vêm provocando grandes alterações nos ecossistemas, sem considerar uma sustentabilidade a curto, médio e longo prazo. O resultado disto é uma crescente degradação ambiental, piorando a qualidade de vida e o bem-estar das populações, sendo que a cada ano são explorados os recursos naturais, desordenadamente, comprometendo a capacidade das futuras gerações de satisfazer as suas necessidades. (BRITO e CÂMARA, 1998)

Visando obter elevada produtividade, além da redução de custos com empregados, o produtor rural aumenta o emprego de máquinas agrícolas, da irrigação e de insumos para aumento da produção: fertilizantes, defensivos, corretivos de acidez do solo, engenharia genética, vacinações e energia elétrica, entre outros. Observa-se, entretanto, que cada um desses fatores de produção causa alguma degradação ambiental, resultando na compactação dos solos, na desertificação, na contaminação dos rios, na perda da biodiversidade genética, nas conseqüências ainda desconhecidas no enfraquecimento de espécies, na expansão descontrolada das fronteiras agrícolas, na destruição de formações vegetais nativas, queimadas na Amazônia e o corte predatório de árvores. (MOURA, 2004).

O consumo dos bens produzidos, efetuado pela população, se torna a peça chave a ser atingida para minimizar a situação de abuso dos recursos naturais, por representar a base do modelo de desenvolvimento econômico capitalista-industrial. Vários mecanismos têm sido desenvolvidos com o objetivo de conscientizar parte da sociedade de que o consumo deve ser feito sem exageros, resultando num convívio sustentável do ser humano com a natureza. Dentre estes mecanismos têmse a Economia Ambiental e seu estudo sobre a valoração dos recursos naturais, a Gestão Ambiental e a intervenção no ambiente com finalidade de recuperá-lo e protegê-lo, e a Legislação Ambiental ditando as normas e regras para uso sustentável dos recursos naturais, sendo que a educação ambiental possui sua parcela de importância dentro destes mecanismos em busca da sustentabilidade (BORGES, 2005).

De acordo com Dias (1999), a educação ambiental é um processo por meio do qual as pessoas podem aprender como funciona o ambiente, como dependem dele, como o afetam e como promovem a sua sustentabilidade. Nesta definição, verifica-se a responsabilidade e importância dada a educação ambiental na busca pela transformação social. 
Considerando esses aspectos, o presente trabalho teve como objetivo avaliar a percepção ambiental de produtores agrícolas, bem como a estrutura e atual estado de conservação de suas respectivas propriedades rurais localizadas no município de Dobrada, Estado de São Paulo, para que estas informações possam fornecer subsídios para o planejamento de programas de educação ambiental na região, bem como a aplicação de políticas públicas capazes de contribuir para resolução de problemas e tomadas de decisões que assegurem a manutenção e conservação do ambiente.

\section{MATERIAL E MÉTODOS}

\subsection{Caracterizações da área de estudo}

O município de Dobrada representado na Figura 1 está localizado na porção nordeste do Estado de São Paulo com vegetação característica de cerrado e mata atlântica. Possui uma população de 7.939 habitantes e uma área de unidade territorial de $150 \mathrm{~km}^{2}$ (IBGE, 2010).

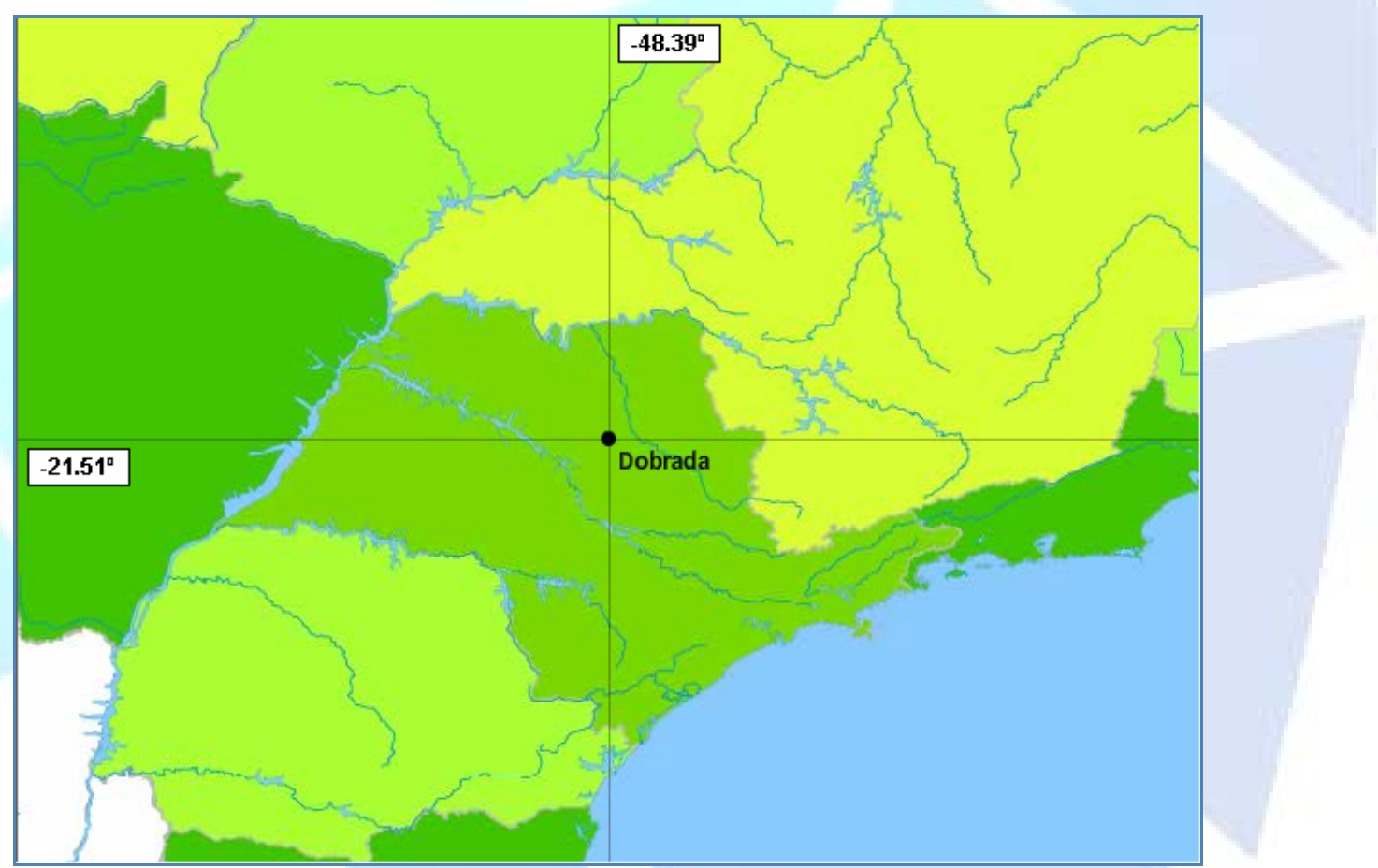

Figura 1. Localização do município de Dobrada, Estado de São Paulo. Fonte: IBGE (2010)

\subsection{Coletas de dados}

Para diagnosticar a situação em que se encontram as propriedades rurais localizadas no município de Dobrada, Estado de São Paulo e a percepção ambiental de seus proprietários, formulou-se um questionário estruturado baseado em Machado (1982) e Martins et al. (2005). Este constitui de 26 questões de caráter sócio-econômico-ambientais e voltadas à percepção e valores relacionados à conservação ambiental, apresentando quadros com diferentes alternativas de respostas e perguntas abertas.

O questionário foi aplicado no ano de 2007 e abordou as questões ambientais mais críticas da atualidade, entre elas, o problema da contaminação por uso de agrotóxicos; descarte de embalagens de defensivos agrícolas e destino final do lixo doméstico; poluentes e ações causadoras 
de assoreamento nos cursos de água; problemas relacionados à conservação do solo e as técnicas de controle; preservação de matas nativas e ciliares, e também, a percepção que o produtor rural tem em relação à importância da conservação e disponibilidade futura dos recursos naturais.

Os formulários foram aplicados nas residências dos entrevistados, abrangendo um total de 30 propriedades rurais, incluindo pequenas, médias e grandes. Os lotes foram escolhidos de forma aleatória, sendo o número de propriedades rurais pesquisadas suficientes para a obtenção dos resultados. O tempo médio utilizado no preenchimento de cada formulário foi aproximadamente de 30 minutos.

\section{RESULTADOS E DISCUSSÃO}

De acordo com os dados sociais levantados neste trabalho observou-se que a maioria das propriedades $(80 \%)$, apresenta uma composição familiar caracterizada por no máximo dois indivíduos (Figura 2), sendo estes, casais cujos filhos abandonaram o campo, residindo e trabalhando em diferentes áreas na zona urbana.

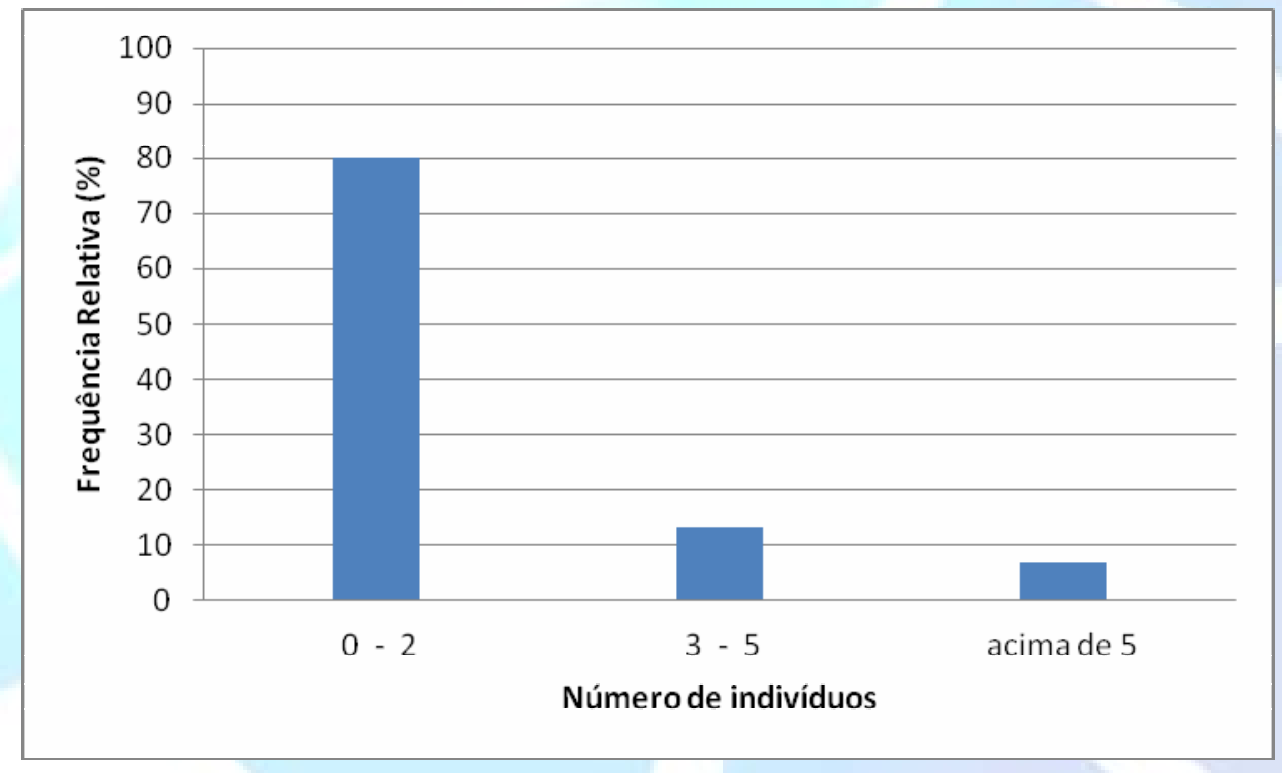

Figura 2. Composição familiar das propriedades rurais estudadas localizadas no município de Dobrada-SP no ano de 2007.

Em relação ao sexo dos entrevistados, houve maior participação do masculino $(79,3 \%)$, o que também ocorreu no grupo de sojicultores em Rio Verde - GO estudado por Barreto (2007) no qual todos os entrevistados eram homens.

Na Figura 3, é possível verificar que a baixa escolaridade ( $1^{\circ}$ grau completo ou incompleto) é marcante no grupo estudado, representando $40,5 \%$ dos entrevistados, enquanto que $31 \%$ possuem o $3^{\circ}$ grau completo. Estes dados coincidem com as informações obtidas por Borges (2005) em seu estudo realizado em áreas de preservação permanente na zona urbana de Uberlândia - MG, no qual mais de $50 \%$ dos entrevistados apresentaram baixa escolaridade. Observou-se também semelhança com a avaliação de Machado (2009) em relação ao grau de escolaridade de cafeicultores familiares entrevistados no município de Inconfidentes $-\mathrm{MG}$, cuja maioria $(70 \%)$ possuía apenas o $1^{\circ}$ grau completo. 


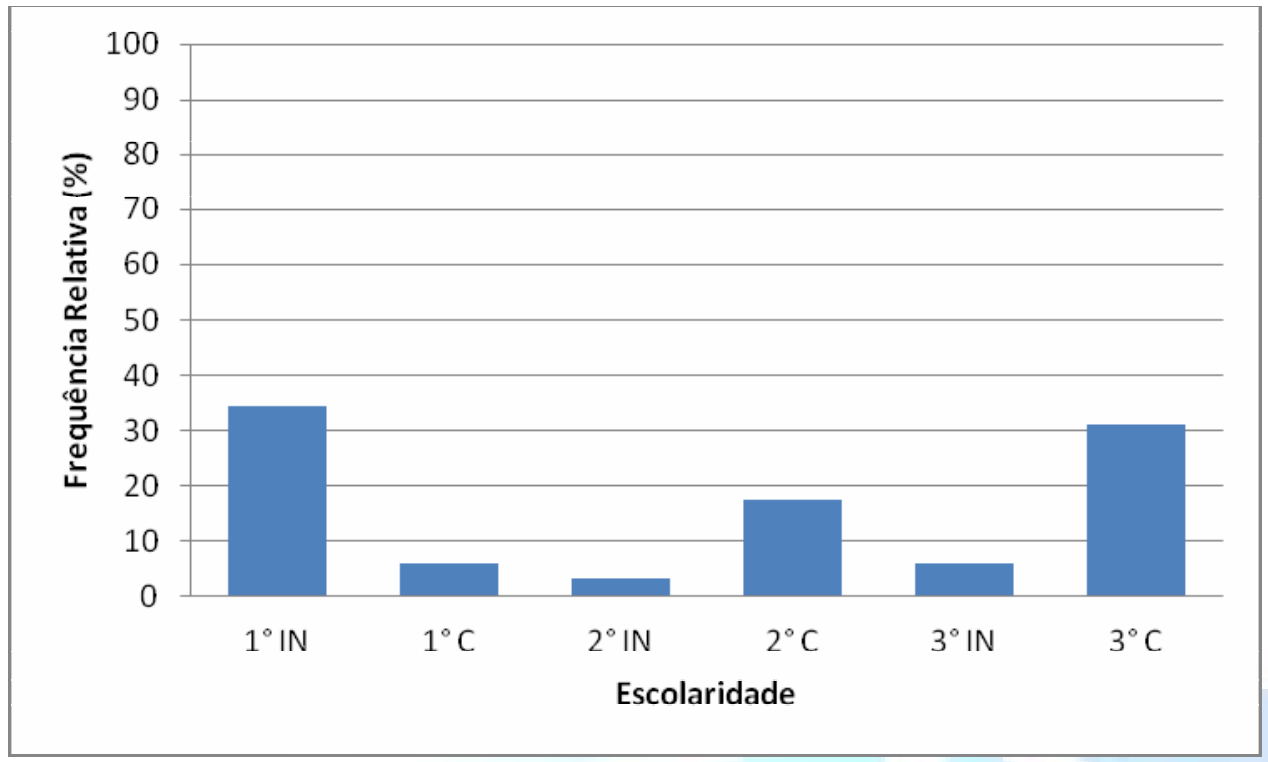

Figura 3. Escolaridade dos proprietários rurais entrevistados no município de Dobrada - SP no ano de 2007. Legenda: IN: incompleto; C: completo

Questões que buscaram caracterizar a produção vegetal e animal, bem como os canais de comercialização destas produções nas propriedades avaliadas mostraram que $80 \%$ delas dedicam-se a agricultura, principalmente de cana-de-açúcar e laranja (Tabela 1). Destaca-se a agroindústria como principal canal de comercialização da produção vegetal (100\% das propriedades), enquanto que no estudo de Barreto (2007), o destino da produção de soja é voltado $56 \%$ para indústria, $24 \%$ para cooperativa, $28 \%$ para exportação e $4 \%$ para mercado.

Nas propriedades que se dedicam tanto a pecuária como a agricultura $(20 \%)$, observou-se uma pecuária voltada principalmente para auto consumo com destaque para produção de aves e bovinos (Tabela 2), sendo $40 \%$ desta produção destinada ao mercado consumidor.

Tabela 1 - Caracterização da produção vegetal nas propriedades rurais avaliadas no município de Dobrada SP no ano de 2007

\begin{tabular}{cc}
\hline Discriminação & Propriedades (\%) \\
\hline Cana-de-açúcar & 86,6 \\
Laranja & 30 \\
Milho & 13,3 \\
Manga & 6,6 \\
Abacate & 3,3 \\
Amendoim & 3,3 \\
Café & 3,3 \\
Limão & 3,3 \\
Hortaliças & 3,3 \\
Mandioca & 3,3 \\
Murcote & 3,3 \\
\hline
\end{tabular}


Tabela 2 - Caracterização da produção animal nas propriedades rurais avaliadas no município de Dobrada SP no ano de 2007

\begin{tabular}{cc}
\hline Discriminação & Propriedades (\%) \\
\hline Aves & 33,3 \\
Bovinos & 36,6 \\
Caprinos & 3,3 \\
Carneiros & 10 \\
Coelhos & 3,3 \\
Equinos & 13,3 \\
Suínos & 16,6 \\
\hline
\end{tabular}

No que se refere à assistência técnica, $100 \%$ das propriedades recebem algum tipo de assistência seja ela através de cooperativas, indústria, casa da agricultura ou particular. De acordo com os dados obtidos, $86,7 \%$ das propriedades recebem assistência de cooperativas, $20 \%$ recebem da indústria, 13,3\% de origem particular e apenas 3,3\% da Casa da Agricultura. Segundo Gomes e Tubaldini (2005), a assistência técnica começa a ser bastante acentuada na agricultura e pecuária a partir da modernização conservadora. No caso de agricultores familiares, ela tem conotação também social, como forma de estes indivíduos se relacionarem com o mundo externo. Em seu estudo com agricultores familiares no município de Caldas - MG apenas 13\% deles faziam parte de alguma associação e $46 \%$ dos produtores requeriam assistência técnica.

Quando questionados sobre o uso de equipamentos de proteção individual (EPIs) adequados para aplicação de agrotóxicos na lavoura, a maioria (73,3\%) afirmou utilizar este tipo de equipamento. Em relação a tríplice lavagem $100 \%$ dos proprietários disseram realizá-la e 96,7\% fazem a devolução das embalagens vazias nos estabelecimentos nos quais os agrotóxicos foram adquiridos, indicando que estes indivíduos possuem consciência dos danos causados por agrotóxicos à saúde humana e ao ambiente e da importância da devolução deste tipo de embalagem, diferenciando-se dos resultados encontrados por Machado (2009), no qual 60\% dos produtores afirmaram não utilizar nenhum equipamento de proteção, $80 \%$ não realizam tríplice lavagem e $60 \%$ devolvem adequadamente as embalagens.

Outro aspecto importante questionado aos agricultores é a forma de eliminação dos resíduos sólidos domésticos, que na maioria das vezes contém embalagens de produtos que demoram centenas de anos para se decomporem causando diversos danos ao meio. Nas propriedades estudadas verificaram-se que $43,3 \%$ queimam este tipo de resíduo, $20 \%$ é coletado pela Prefeitura uma vez por semana nas propriedades que se localizam a uma distância de até $4 \mathrm{~km}$ da área urbana, $16,6 \%$ enterram, $6,6 \%$ o deixam a céu aberto e $13,5 \%$ não geram este tipo de resíduo por não residirem em suas propriedades. Vale salientar que os resíduos coletados pela Prefeitura são destinados a um lixão municipal localizado a $6 \mathrm{~km}$ do município. Em parte estes resultados coincidem com os relatados por Gomes e Tubaldini (2005) que registraram a queima como principal destino dos resíduos gerados nas propriedades.

Esses dados apontam uma falta de consciência ou talvez ausência de informação a respeito dos sérios problemas relacionados à poluição, principalmente do solo e do ar, e no caso dos resíduos que são deixados a céu aberto pode ocorrer maior procriação de agentes transmissores de doenças.

Problemas relacionados à conservação do solo nas propriedades também foram registrados, observando-se que $63,3 \%$ das propriedades possuem assoreamento de cursos d'água, 16,6\% erosão e 3,3\% voçoroca. Das propriedades estudadas $86,7 \%$ apresentam algum curso de água (rio, córrego 
ou nascente), dos quais $40 \%$ apresentam algum tipo de contaminação mencionada pelos agricultores.

Após análise sócio-econômica-ambiental das propriedades, os agricultores responderam questões nas quais deveriam atribuir algum tipo de importância a conservação da água, solo, mata ciliar, florestas e animais silvestres para que através de suas respostas fosse possível diagnosticar o nível de percepção ambiental dos produtores rurais do município de Dobrada-SP.

$\mathrm{Na}$ questão referente à importância da conservação da água, constatou-se que $40 \%$ das respostas justificaram este recurso como sendo um bem essencial à vida contrapondo com $13,3 \%$ de respostas que consideram água como bebedouro para gado (Tabela 3 ).

Tabela 3 - Importância que os proprietários rurais entrevistados no município de Dobrada- SP atribuíram à conservação da água, no ano de 2007

\begin{tabular}{cc}
\hline Importância atribuída & Entrevistados (\%) \\
\hline Essencial a vida & 40 \\
Evitar escassez & 33,3 \\
Benefícios as agricultura & 20 \\
Manutenção da umidade & 13,3 \\
Bebedouro para gado & 13,3 \\
\hline
\end{tabular}

A conservação do solo é vista pela grande maioria dos proprietários $(96,7 \%)$, como uma prática importante simplesmente para aumentar sua renda, sem considerar a preservação do ambiente e das outras formas de vida que dele dependem, sendo que apenas 3,3\% atribuíram a importância da conservação do solo à preservação da vida.

Quando os agricultores foram interrogados sobre a importância da conservação das matas ciliares, verificou-se que $70 \%$ dos proprietários relacionaram a sua importância a preservação dos cursos de água e 23,3\% justificaram que essas matas são habitats para animais silvestres (Tabela 4). De acordo com as respostas percebe-se que os indivíduos possuem uma consciência ambiental em relação às matas ciliares, mas não estão sabendo aplicar medidas corretas de conservação, pois se mencionou anteriormente, que as propriedades apresentavam problemas de erosão e assoreamento.

Considerando-se a avaliação de Barreto (2007), observa-se que os sojicultores de Rio VerdeGO entrevistados apontaram motivos semelhantes ao dos agricultores de Dobrada- SP em relação à conservação das matas ciliares. Segundo esse autor, 34,61\% dos sojicultores mencionaram a preservação e conservação de nascentes e rios, $13,46 \%$ associaram a prevenção do assoreamento e $11,59 \%$ acharam importante manter a vegetação ciliar por causa dos animais.

Tabela 4 - Importância que os proprietários rurais entrevistados no município de Dobrada - SP atribuíram à conservação das matas ciliares, no ano de 2007

\section{Importância atribuída}

$$
\text { Preservação dos cursos d'água }
$$

Habitat para animais silvestres

Proteção do solo

Conservação da umidade do solo

Respiração

\section{Entrevistados (\%)}

16,7

13,3

3,3 
Além do valor das matas ciliares, abordou-se a questão sobre preservação e conservação de matas e florestas nas propriedades. A maioria dos entrevistados $(56,7 \%)$ relacionou a sua importância como sendo abrigo de animais silvestres, 33,3\% acreditam que elas possam melhorar as condições do ar, 16,7\% acham que as mesmas evitam mudanças climáticas, 13,3\% associaram a preservação de espécies vegetais, $10 \%$ mencionaram sobre a sombra que proporcionam nas propriedades e 6,6\% afirmaram que são importantes para evitar problemas de erosão.

No questionamento sobre os animais silvestres, observou-se que $40 \%$ atribuem a importância da sua conservação a não extinção de espécies e equilíbrio das cadeias alimentares, sendo que 3.3\% dos agricultores não atribuíram importância aos mesmos (Tabela 5).

Tabela 5 - Importância que os proprietários rurais entrevistados no município de Dobrada- SP atribuíram à conservação dos animais silvestres, no ano de 2007

\begin{tabular}{cc}
\hline Importância atribuída & Entrevistados (\%) \\
\hline Cadeia alimentar & 40 \\
Não extinção de espécies & 40 \\
Beleza & 16,6 \\
Dispersão de sementes & 6,6 \\
Nenhuma & 3,3 \\
\hline
\end{tabular}

\section{CONCLUSÕES}

Considerando os dados obtidos neste trabalho, pode-se concluir que existe uma falta de informação ou conscientização a respeito dos problemas de poluição do solo, agua e ar, bem como das praticas conservacionistas de solo, pois os proprietários rurais não dispõem adequadamente seus resíduos sólidos e apresentam em suas propriedades problemas de erosão e assoreamento de corpos hídricos.

Assim, há necessidade de melhores esclarecimentos aos agricultores através da educação ambiental, pois suas respostas sobre a importância da preservação e da conservação dos recursos naturais na maioria das vezes não refletem a verdadeira situação de suas propriedades, já que estes mostram ter alguma percepção ambiental, a qual, porém, não é colocada em prática, muitas vezes por falta de informações e conscientização.

\section{REFERÊNCIAS}

BARRETO, C.A. Agricultura e meio ambiente: percepções e praticas de sojicultores em Rio Verde - GO. 2007. 138f. Dissertação (Mestrado em Ciência Ambiental) - Faculdade de Saúde Pública, Universidade de São Paulo, São Paulo, 2007.

BORGES, D.J.V. As condições socioambientais de áreas de preservação permanente na zona urbana de Uberlândia: Aspectos Paisagísticos e Sociais. 2005. 100f. Dissertação (Mestrado em Ecologia de Recursos Naturais) - Universidade Federal de Uberlândia, Uberlândia, 2005.

BRITO, F.A.; CÂMARA, B.D. Democratização e Gestão Ambiental: em busca do desenvolvimento sustentável, 2.ed. Petrópolis, RJ: Vozes, 1998, p.36-42. 
DIAS, G.F. Elementos para capacitação em educação ambiental. Ilhéus: Editus, 1999. 186p.

GOMES, I.; TUBALDINI, M.A.S. A percepção ambiental na agricultura familiar. In: Simpósio Nacional sobre Geografia, Percepção e Cognição do Meio Ambiente, 1. 2005, Londrina.

Anais...Londrina: UEL, 2005. p.1-11.

INSTITUTO BRASILEIRO DE GEOGRAFIA E ESTATÍSTICA - IBGE. Cidades@: Dobrada SP. [S.I.: s.n], 2010. Disponível em: <http //www.ibge.gov.br/cidadesat/default.php>. Acesso: 10 jan. 2011.

MACHADO, A.B.M. Conservação da natureza e educação. Silvicultura em São Paulo, v.16, n.1, p. 109-118, 1982.

MACHADO, T.F. Avaliação da percepção ambiental de cafeicultores familiares do município de Inconfidentes, Sul de Minas Gerais. 2009. 43f. Trabalho de Conclusão de curso Superior de Tecnologia em Gestão Ambiental - Instituto Federal de Educação, Ciência e Tecnologia do Sul de Minas Gerais - Campus Inconfidentes, Minas Gerais, 2009.

MARTINS, M.; CARVALHO, S.L.; FREITAS LIMA, E.A.C; ARAUJO, C.A.M. Avaliação das condições socioeconômicas de algumas propriedades agrícolas no município de Ilha Solteira/SP. In: Congresso Brasileiro de Administração Rural, 5. 2005, Campinas. Anais... Campinas, 2005. p.1-16.

MOURA, L.A.A. Qualidade e Gestão Ambiental, 4.ed. São Paulo: Juarez de Oliveira, 2004, 389p. 